\title{
West Midlands
}

\section{Map 6.5 Population density: by local or unitary authority, 2008
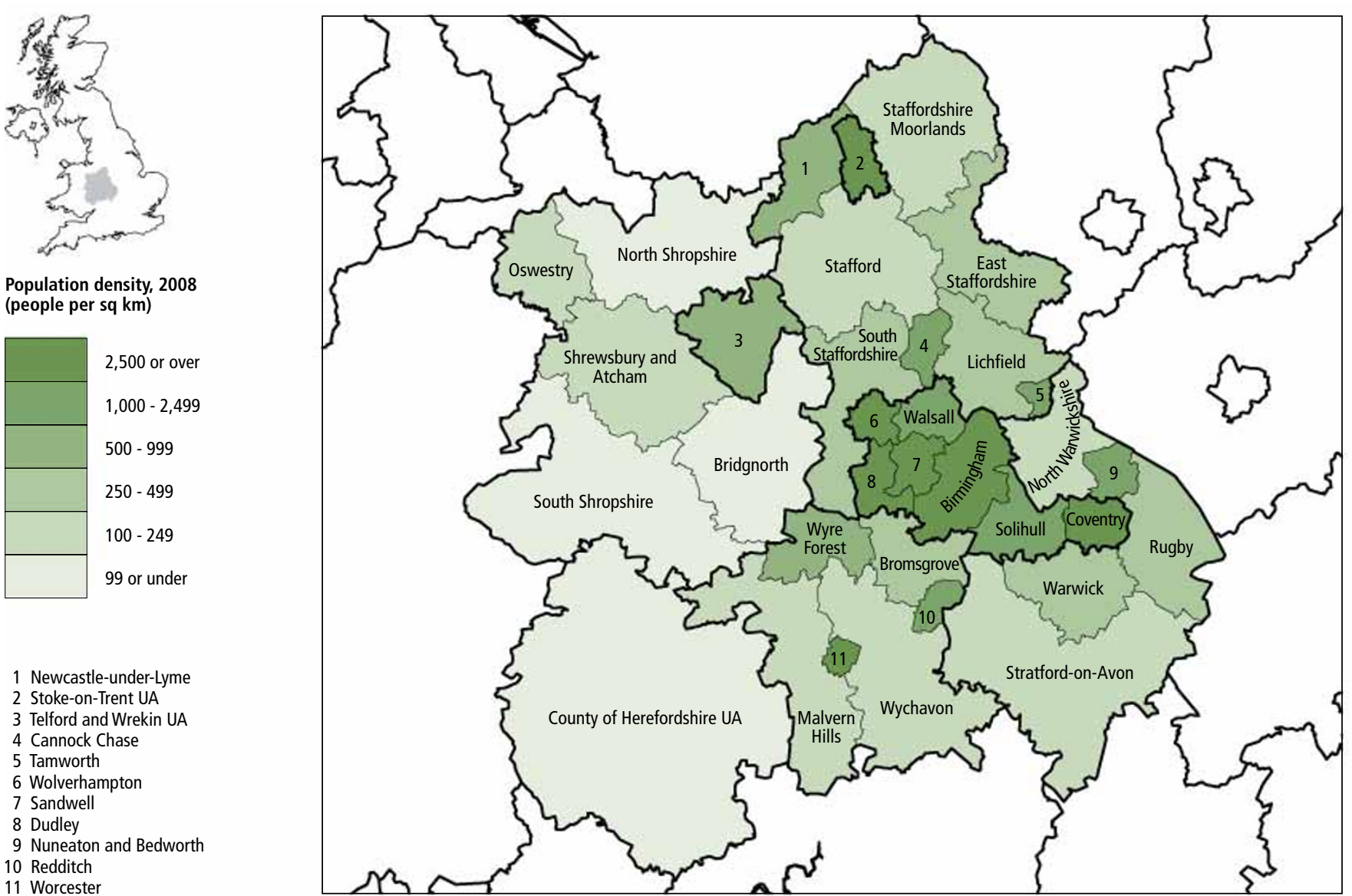

1 Newcastle-under-Lyme

2 Stoke-on-Trent UA

3 Telford and Wrekin UA

4 Cannock Chase

5 Tamworth

6 Wolverhampton

7 Sandwell

8 Dudley

9 Nuneaton and Bedworth

10 Redditch

11 Worcester

- The West Midlands had a population of 5.4 million in mid-2008, an increase of 1.9 per cent since 2003. This compares with an overall increase of 3.1 per cent for the UK over the same period (Online table 1.2).

- People over state pension age (65 and over for men and 60 and over for women) in the West Midlands in 2008 made up 19.7 per cent of the population, compared with 19.4 per cent for the under-16s. This compares with averages for the UK of 19.2 per cent and 18.8 per cent respectively.(Online table 10.3).

- In the West Midlands, men aged 65 in 2006-08 could expect to live another 17.4 years and women 20.1 years. This compares with 17.5 and 20.2 years in the UK as a whole (Online table 6.8).

- In the West Midlands, 46.1 per cent of pupils achieved five or more grades $A^{*}-C$ at GCSE level or equivalent including English and mathematics in 2007/08, compared with 47.7 per cent for the UK as a whole (Online table 4.8).
- The unemployment rate in the West Midlands stood at 9.4 per cent in the fourth quarter of 2009, higher than the UK rate of 7.8 per cent (Online table 1.1).

- A higher proportion of children in the West Midlands (19 per cent) lived in workless households in the second quarter of 2009, than the England average of 17 per cent (Online table 8.6).

- In April 2009, the median gross weekly earnings for full-time employees on adult rates who were resident in the West Midlands was $\mathrm{f457}$, lower than the UK median of f489 (Online table 9.19).

- Labour productivity (gross value added per hour worked) in the West Midlands in 2008 was 10.4 per cent below the UK average (Online table 3.2).

- Local authorities in the West Midlands recycled 33 per cent of household waste in 2007/08 compared with an England average of 35 per cent (Online table 5.11). 